\title{
Profit: The Cause of Crisis in Capitalism
}

\author{
By Sašo Tomažič
}

In this paper, we show that the main reason for the recurring crises is integrated into the very foundation of capitalism. The reason lies in the fundamental premise of capitalism that capital must yield profits. This premise demands a constant growth (e.g., 2\% per anum) of a real economy. Such growth is exponential. Sooner or later, this premise yields lack in demand and lack of natural resources, resulting in economic crises, wars, and ecological catastrophes. In this context, the profit gained from financial capital represents the greatest problem. All money, including newly created money, is loaned for interest, which means that interest must be paid for all the money in circulation. However, this demonstrates that the debt arising from interest cannot be repaid, which is the main reason why all the countries in the world are in fact in debt, with the public debt ranging from $75 \%$ to $260 \%$ of GDP. A profitbased economy has built-in positive feedback. As is well known in system theory, systems with positive feedback are unstable, meaning that a profit-based economy is also unstable. The only way to establish a stable, sustainable and fair economic system is to slowly start reducing profits and begin building an economy that is not driven by profit. The first steps that we can take in this direction are to establish better education, to increase social security, and to reform monetary system, including reform of the banking system and progressive taxation of profits. The latter is especially vital in this respect as progressive taxation not only reduces the adverse effects of profit on the general economy but also introduces negative feedback into the economic system, thus stabilizing it in the long run.

Keywords: profit, crisis, interests, capital, positive feedback.

\section{Introduction}

In capitalism periods of high economic growth and prosperity are followed by periods of crisis and recession. A number of economic crises have occurred in the last hundred years, including the Depression of 1920/21 in the USA, which observed extreme deflation and economic collapse; the Wall Street Crash of 1929 and the Great Depression that followed it, which only truly ended with World War II; Black Monday in 1987, when crashes in all stock markets followed the plummeting share prices in Hong Kong; the savings and loan crisis in the USA in the eighties; the bursting of the dot-com bubble in 2000; the Irish banking crisis in 2008/10; and, of course, the financial crisis in 2008, which still continues, to name just a few.

This phenomenon was first systematically discussed in 1819 by J. C. L. de Sismondi (Sismondi, J. C. L. 1827), who cited excess output and insufficient consumption as the main causes of the crises, arising primarily as a result of the large gaps between the rich and the poor. One of the most excellent

${ }^{*}$ Head of ICT Department, University of Ljubljana, Faculty of EE, Slovenia. 
analysis was presented by K. Marx, in 1867, in his book the "Capital: Critique of Political Economy" (Marx. K. 1867), which argued that only work can create new value. Unfortunately, he envisioned the transition to communism by revolution, which resulted in many nondemocratic communist regimes. J. M. Keynes (Keynes, J. M. 1936) further developed these ideas. He was confident that the free market is not self-regulative and that government intervention is necessary to obtain full employment. He even predicted that a 15-hour workweek would be sufficient and necessary to attain full employment in the $21^{\text {st }}$ century. His theory significantly impacted post World War II macroeconomic policy, in the Golden Age of Capitalism, until 1979, when the idea of free markets (laissez-faire) began to dominate economic thought again.

Many different macroeconomic models were developed to predict and prevent reoccurring economic crises. They range from simple theoretical models with a small set of variables to large-scale empirical models that use large amounts of data from the past and dynamic stochastic general equilibrium models (DSGE) that use agents (i.e., households, firms, banks, etc.), each with different objectives, to simulate processes in the real-world economy. A database of various macroeconomic models is freely available at The Macroeconomic Model Data Base (MMB 2016).

All macroeconomic models have in common that the results they provide depend on the set of assumptions made when building and using them. These assumptions can be either correct or incorrect; however, it is highly unlikely that all assumptions are correct, e.g., that we set the objectives of all agents in DSGE model realistically and that they reflect the behavior of real word agents. This is probably the main reason why all these models failed to predict (or prevent) the crisis in 2008. Even if the assumptions were all correct and a model gave accurate predictions, it would be very difficult to use it to understand why crises occur and the real reason for economic fluctuations. There are too many variables that we can alter, and even if we would find their optimal values, we would hardly be able to guess why these values are optimal.

In this paper, we show that capital profit is the main reason for economic fluctuations and that a profit-based socio-economic system is inherently unstable. Most economists consider economic fluctuations to be unavoidable as a natural phenomenon. However, a socio-economic system is not a natural phenomenon. It is human designed; thus, we believe that humans can redesign it in such a way that it will become stable.

\section{Methodology}

As previously mentioned, different macroeconomic models are used to analyze processes in the economy and predict the outcomes of different measures taken to achieve a specific goal (e.g., prevent crisis). Simple models, such as AD-IA (Aggregate Demand - Inflation Adjustment), IS-LM (Investment Saving - Liquidity preference Money supply), IS-MP (Investment Savings- Monetary Policy), and similar consider only two or three economic 
parameters and analyze their mutual dependence. They neglect all other parameters that may or may not influence the parameters under investigation.

However, macroeconomic models, such as LSMM (Large Scale Macroeconomic Model), ACE (Agent-based Computational Economics), and DSGE (Dynamic Stochastic General Equilibrium) are very complex and consider many different parameters. However, they are also based on many assumptions that could or could not be correct. For instance, agent-based macroeconomic models usually assume that economic agents (i.e., households, companies, banks, and so forth.) behave rationally and that they perform in such a way to optimize their objectives. Are they always rational? Are their objectives set correctly? Do all agents of the same type have the same objectives? These are questions that are difficult to answer. However, changing any of the assumptions can significantly alter the output of the model.

In this paper, we use an alternative approach. We try to avoid different assumptions, and we base our reasoning on common logic. We observe the big picture, avoiding being lost in the details and not seeing the forest from the trees. We can best describe our methodology by the following example of marble collectors.

In this example, marble collectors have a trade meeting in a marble's club. Each collector brings his marbles to the club, the clubhouse doors close and bargaining begins. There is no facility to produce new marbles in the club. There can be very different and sophisticated ways to exchange marbles. They can buy or sell them. They can play different games to win the marbles of their competitors. They can trade them in a variety of ways; for example, one can be prepared to give five of his yellow marbles for one red marble to fulfill his collection. They can even steal marbles from each other.

However, without knowing any of these details, we can arrive at the conclusion that the total number of marbles at the end of the meeting is the same as it was at the beginning of the meeting unless they destroyed some marbles. We can also know for certain that, if someone has more marbles at the end than at the beginning, other collectors must have fewer marbles at the end than at the beginning. If someone had gained marbles, somebody else must have lost them. In physics, this is known as the law of conservation of matter.

This is the type of reasoning we use in our analysis.

\section{Economic Equilibrium}

Economists around the world try to find economic equilibrium, i.e., the state of the economy when different economic forces are in balance, such as when the supply meets the demand and the unemployment rate is at a constant and low level. Simple mathematical models involve solving sets of equations and inequalities. More complex models involve supercomputers, different sophisticated optimization algorithms, machine learning, and artificial intelligence. However, if the assumptions (explicit or implicit) of the models are incorrect or if they neglect some critical parameters, the results are 
misleading, which was evident when these models failed to predict the 2008 crisis.

Even if one of the complex models (simple models are too simple) were correct and could find an equilibrium state, there would be no guarantee that this state is stable, and most likely, it would not show how to arrive at that state and remain there.

In physics, it is well known that the state of equilibrium can be stable or unstable. Stable systems tend to remain in the state of equilibrium, and unstable systems tend to leave this state. For example, a stick that we hold with our fingers so that it hangs down (Figure $1 \mathrm{a}$ ) is in the state of stable equilibrium. For any deviation from this state, the force of gravity acts in the direction of the stable equilibrium.

Figure 1. Stable (a) and Unstable (b) Equilibrium. A System in an Unstable Equilibrium Requires Regulation (proper hand movements) to Remain in that State

(a) stable

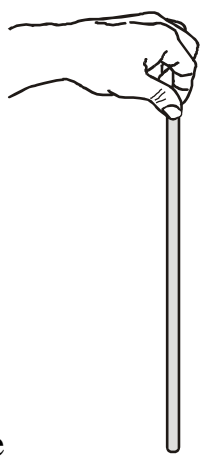

(b) unstable

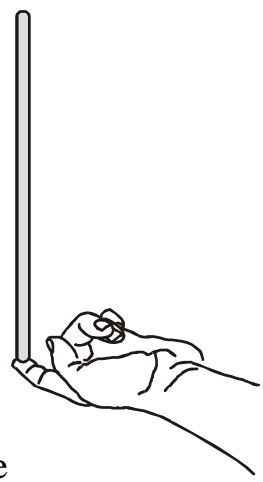

However, a stick that one holds on his finger pointing upwards (Figure 1 b) is in an unstable equilibrium. For any deviation from this state, the gravity force acts in the direction away from the equilibrium state. Proper regulation (hand movement) and certain skills are required to keep the stick in balance.

When the output (the result) of a system changes its input (the cause), it is called feedback. From system theory, it is well known that systems with positive feedback are unstable. The feedback is positive when output changes the input constructively, i.e., when the result increases its cause. Systems with positive feedback can also be in the state of equilibrium; however, this equilibrium is unstable. They cannot remain in equilibrium without regulation.

Regulation represents negative feedback (the result decreases its cause). Systems with negative feedback are stable, except when the feedback is delayed. When negative feedback is delayed, it causes the system to oscillate; thus, delayed regulation can cause the oscillation of the system output. 


\section{Profit from Capital}

We can make a profit from the capital by investing or by lending money for interest. Both mechanisms introduce positive feedback into the economic system.

When we add the profit (the result) to the investment capital (the cause), the capital increases, which causes the increase in profit. The positive feedback loop closes. The capital then grows exponentially, according to the equation:

$F=\frac{c}{C_{0}}=C_{0}\left(1+\frac{p}{100}\right)^{n}$,

where $F$ is the growth factor, $C$ is the capital after $n$ years, $C_{0}$ is the invested capital at the beginning, and $p$ is the percentage of profit per annum. The exponential grow of capital also requires the exponential growth of the real economy by the same factor.

Economists become worried when the economic growth is less than $2 \%$ per annum. The growth of $2 \%$ per annum seems moderate in the short term; however, it is not feasible in the long term. Eventually, we run out of natural resources and new markets.

If the yearly growth were truly $2 \%$ per annum from the beginning of our era, a winery that produced only 100 liters of wine 2,017 years ago would now produce more than 3 billion liters of wine for each of the 7 billion inhabitants of the planet Earth each year. Obviously, the growth of the real economy cannot be $2 \%$ per anum in the long term.

In the short term, we can acquire economic growth by always looking for new markets and by artificially creating new needs and increased demand. However, there is not an infinite number of new markets, and the demand cannot grow beyond all limits. No advertising can achieve that a person would drink eight million liters of wine a day. Moreover, there is not enough natural resources and workforce to produce such quantities of wine. The same holds for any other commodity.

In order maintain a short-term economic growth, and in this way enable the capital to yield profit, things must be destroyed from time to time, which occurs in wars and crisis. A good example of the about statement is the Great Depression of 1929. With a great number of highly beneficial and successful programs (public works, social transfers, and agreements with trade unions, just to name a few), the "New Deal" alleviated some of the problems caused by the economic downturn. However, the crisis did not end until after World War II, in which many buildings, factories, roads and other things were destroyed and needed to be rebuilt after the war. Not even mentioning the rise of the war industry during the war.

A similar problem occurs when banks lend money for interest. The interest rate on loans is usually higher than $2 \%$, approximately $5 \%$ per annum. At this rate, one euro borrowed 2,017 years ago would yield a debt of $5.48 \cdot 10^{42}$ euros. Even if one could print $€ 1,000,000$ banknotes, the mass of the paper 
required to print enough banknotes to pay this debt would exceed the mass of a billion Suns.

All newly created money is lent for interest; thus, interest should be paid for all the money in circulation. At a 5\% interest rate, the debt doubles in approximately 14 years. Therefore, after 14 years, banks expect to have twice as much money than they created. If the bank created one billion euros, the debt after 14 years would be two billion. As the bank created only one billion euros, this debt is not payable. There is not enough money to pay this debt. The debt arising from interest cannot be repaid, even not in theory.

Moreover, approximately $95 \%$ of the money in circulation is from a loan from commercial banks. They create this money from nothing and still expect to make a profit by lending it.

Because the interest on loans cannot be repaid and all the money in circulation represents a loan, this necessarily leads to debt crises. The 2008 global financial crisis was the result of increasing indebtedness. Many contribute this crisis to irresponsible and even fraudulent practices of banks and other financial institutions, which were inventing ever new, suspicious financial instruments like, for example, collateralized debt obligations (CDOs). In fact, with CDOs banks created new private money, which was necessary because of the increasing indebtedness, which only delayed the crisis for a while. The Crisis of 2008 would have also occurred without all these financial inventions, most probably even earlier. However, it would have had a less devastating impact.

After 2008, the government tried to overcome the crisis with the rehabilitation of banks, austerity measures and issuing large amounts of new money, which supposedly ended the crisis. In April 2009 TIME magazine declared that the crisis was over more quickly than it had begun. However, the main problem remained. All countries are now even more indebted than they were in 2008. According to IMF, the total debt of the non-financial sector (i.e., companies and households) to the financial sector at the end of 2015 was $\$ 152$ trillion, and it is steadily growing. Without any change in the monetary system, this will, sooner or later, yield another debt crisis.

A paradox of profit based economy is that the non-financial sector which produces goods owes to the financial sector which does not produce anything.

Another example of positive feedback caused by profit is the positive feedback in the labor market. Due to advances in production technology, work efficiency has significantly increased, particularly in the beginning of $21^{\text {st }}$ century. One worker can now produce much more (ten or even hundred times more) than at the beginning of $20^{\text {th }}$ century. The demand for work is, thus, continuously decreasing. Instead of reducing the workload of employees (i.e., reducing work hours), employers reduce the number of employees to make more profit. Due to an increase in unemployment, purchasing power declines, which causes a decrease in demand. Even more workers lose their jobs, and the positive feedback loop closes.

Governments try to solve this problem by regulation, using different measures to reduce unemployment. Proper regulation represents negative 
feedback; however, as it usually occurs after much delay, it causes oscillations in the economy, called the business cycle or economic fluctuations.

This process was very obvious during the Great Depression as well as after the 2008 financial breakdown. According to Eurostat, in Greece, which was hit the most by the 2008 crisis, the unemployment rate increased from $8.4 \%$ in 2007 to $27.5 \%$ in 2013 , when it started slowly decreasing, to $24.9 \%$ in 2015 , as a consequence of the delayed measurements taken by the government.

\section{Possible Solutions}

Under capitalism, we cannot avoid crises, because their cause is integrated into the very foundations of the economic system-in its proposition that capital must generate profit. Throughout history, advances in science, technology, and the collective consciousness have transcended the limits of the existing socio-economic system. Change is and has always been inevitable: societies have shifted from slavery to feudalism, from feudalism to capitalism, and from capitalism to socialism. In the opinion of the author, a change from socialism to capitalism represents a step backward.

For real change to occur, we must cut the positive feedback loop and thus renounce the profit that comes from capital. The society should transform to, what we can name, a non-profit society - a society in which greed is not the only motivation for progress, a society in which profit does not govern every decision.

Here we propose some steps that we could make towards a non-profit society. Although these are not the only possible steps, they are, as we strongly believe, the steps in the right direction. They should be seen only as suggestions which need further elaboration.

\section{Raising Collective Consciousness}

Raising collective consciousness is the first and the most important step for any change to happen. People should first understand why changes are necessary and what kind of changes are required to avoid future crises, new wars, global pollution, and ecological disaster. Only then politicians will be elected based on the programs that lead in the right direction, towards building a better, more stable and just society.

It all begins with education. We obtain most of our moral values in early childhood. Children should thus be thought high moral values already in primary school. Education is not only for obtaining knowledge. Children should understand that collaboration is far better than competition, that care for others can be much more rewarding than only care for themselves, that there are greater values in life than money, and that there can be greater goals than just to get rich. 


\section{Redefinition of Private Property}

Private property is one of the mechanisms to generate profit. While personal property is perfectly acceptable, private ownership of natural resources and means of production is not acceptable, because the only reason behind this kind of property is profit. Ownership of means of production is only acceptable when the owners are the workers who utilize these means. Many successful companies already work on this principle. Mondragon Corporation in the Basque region of Spain employs more than 74 thousand employees, which are also the owners of the corporation. On their web portal, they report total revenue of 12 billion $€$.

We must treat all natural resources as a common good. They are nobody's property, as well as the seas and the oceans are not. Fishers do not need to own a sea to fish in it. Governments already regulate the rational exploitation of seas and oceans. Similarly, exploitation of all other natural resources should also be regulated by governments.

\section{Monetary Reform}

Debt creating money is one of the major causes of reoccurring crises. Partly this problem would be solved by seigniorage reform proposed by Joseph Huber and James Robertson (Huber, J. \& Robertson, J. 2000). They propose that

- central banks should create the amount of new non-cash money (as well as cash) they decide is needed to increase the money supply, by crediting it to their governments as public revenue, and

- it should become infeasible and be made illegal for anyone else to create new money denominated in an official currency.

A step further would be made by depriving money of its function of profit generating capital. Money should become only a means of exchange, i.e., a record of the uncompleted exchange. Many local exchange trade systems (LETS) in which money is only means of exchange already function all over the world, the largest being Swiss WIR Bank, which helped Swiss to avoid many financial crises.

\section{Introduction of Progressive Taxation and Maximum Income}

The governments should progressively tax profits as well as all other incomes. Incomes that exceed a certain limit (the maximum income) should be taxed $100 \%$. Such taxation would cut the positive feedback loop created by profit. Thus, there would be no more need for the exponential growth of the economy. 
In the Golden Age of Capitalism in the USA the progressive tax on profit could reach up to $90 \%$ until the reestablishing of free market "laissez-faire" model in 1980s.

\section{Shortening Work Week}

Due to the great technological progress of the $20^{\text {th }}$ and $21^{\text {st }}$ century, work efficiency increased dramatically. With contemporary technology, one can produce ten to hundred times more than he could at the beginning of the last century. However, the number of weekly working hours stayed nearly the same.

Because employers want to increase profit, they prefer to reduce the number of employees instead of reducing the workload. Unemployment is becoming one of the greatest problems of contemporary society. It creates positive feedback and makes the economic system unstable.

Governments should shorten work week, which would in great extent solve the problem of unemployment. However, it would be very difficult to do it locally, only in one country, due to the global concurrence and competition for markets. In spite of this obstacle, Sweden has already shortened work week. However, France who had shortened work week before had to prolong it back, to be competitive in the global market.

The attitude towards work will also have to change. Shortly machines and robots with built-in artificial intelligence will be able to perform virtually all routine work.

Work will become a privilege. The ability to contribute to the community will become the greatest reward, which is already happening in certain areas of human activity. Many people write computer programs for free, give free advises on social networks, write reviews on platforms as Trip Advisor, perform voluntary charity work, and so on and so forth. They do all this just to help others, just to get recognition for their work.

\section{Increasing Social Security}

Social security has a major impact on quality of life. In countries with a high degree of social security, we perceive significantly less crime. Today, it would not be difficult to provide for the basic needs of all citizens. We could deal with famine in the world only by the share of food every day dismissed.

Lately, as the appropriate mechanism for the elimination of poverty universal basic income (UBI) is often mentioned - even in serious political and economic circles. UBI is the income that would be received by all citizens, irrespectively of their age and irrespectively of whether they are employed or not. UBI should be high enough to exceed the threshold of poverty.

In the long run, it would be more rational to combine UBI with the provision of certain goods to all citizens free of charge. Here we have primarily in mind the basics commodities needed for a decent life. For example, with the introduction of free food, the amount of food waste would be significantly 
reduced, as the effect of the "breakfast buffet" would occur. Most of the major hotels in the world have introduced a breakfast buffet. In this way, they waste less food, while the customers are much more satisfied.

On the one hand introducing free food would solve the problem of hunger, and on the other hand, it would make the consumption of food considerably more efficient.

A similar effect would arise from making transportation and other commodities free as well. Just think about all the cars in a city, which are parked almost all of the day.

\section{Conclusions}

We have shown that capital profit introduces positive feedback into the economic system. The systems with positive feedback are unstable. As profit from capital is integrated into the very foundation of capitalism, we can state that capitalism is inherently unstable.

Capital profit requires an exponential growth of the economy, which is impossible even theoretically, which yields a lack of natural resources, evergreater pollution, global climate changes, economic crisis, and wars.

Furthermore, the interest for loans cannot be paid, which yields everincreasing debt and debt crises. Due to advances in technology, the demand for work is decreasing. As employers want to increase their profits, they reduce the number of employees, which introduces another example of positive feedback into the system.

We can conclude that a profit based economy has been outgrown in an era when practically all jobs can be automated. Almost everything can be made by machines, robots, and computers. There is much more supply than demand. It is no more a problem to produce something; it is a problem to sell it.

Contemporary economists do not question capital profit; however, to make an economic system stable and avoid further repeating crises, ecologic catastrophe, and wars, it would be necessary to build a new economic system that is not based on profit.

\section{Acknowledgments}

The Slovenian Research Agency partly financed the research in this paper under research program P2-0246.

\section{References}

Sismondi, J. C. L. 1827, Nouveaux principes d'économie politique ou de la richesse dans ses rapports avec population, seconde edition, Delaunay, Paris.

Marx. K. 1867, Capital: A Critique of Political Economy, Vol I-III, Cosimo Clasic, New York (Dec. 2007, originally published 1867). 
Keynes, J. M. 1936, The General Theory of Employment, Interest, and Money, Prometheus Books (1997, originally published 1936).

MMB 2016, The Macroeconomic Model Data Base, http://www.macromodelbase. $\mathrm{com} /$, accessed 02. 10. 2016

Huber, J. \& Robertson, J. 2000, Creating new money, a monetary reform for the information age, New Economics Foundation, London. 
